- Original Article

\title{
The Relationship of Caffeine Intake with Depression, Anxiety, Stress, and Sleep in Korean Adolescents
}

\author{
Mi-Joo Jin', Chang-Ho Yoon ${ }^{1 *}$, Hae-Jin Ko', Hyo-Min Kim', A-Sol Kim', Ha-Na Moon', Seung-Pil Jung ${ }^{2}$ \\ 'Department of Family Medicine, Kyungpook National University School of Medicine, Daegu, Korea \\ ${ }^{2}$ Department of Family Medicine, Yeungnam University College of Medicine, Daegu, Korea
}

\begin{abstract}
Background: In various studies in adults, caffeine may increase wakefulness and relieve pain, but caffeine overdose can cause many adverse serious effects on health. Caffeine intake has recently been increasing in adolescents. In spite of importance of caffeine effects on Korean adolescents, there are lack of scientific and systematic studies. The purpose of our study was to identify the relationship between caffeine consumption and effects on adolescents. Methods: We performed study on 234 middle school students at one middle school in Daegu using a self-report questionnaire. We divided students to quartiles according to amount of caffeine intake. We used Beck Depression Inventory (BDI) to evaluate the degree of depression and Beck Anxiety Inventory (BAI) to evaluate the degree of anxiety. We also used Insomnia Severity Scale (ISI) to evaluate the degree of insomnia and Global Assessment of Recent Stress (GARS) to evaluate the stress in students. We used logistic regression analysis to identify the relationship between caffeine consumption and effects.

Results: Higher caffeine intake was associated with higher weight, height, lower academic achievement, and higher score in BDI, BAI, ISI, and GARS (P for trend $<0.005$ ). Higher caffeine intake quartile was associated with greater odds of having significant depression ( $\mathrm{BDI} \geq 10$, $\mathrm{P}$ for trend $=0.011$ ), and insomnia (ISI $\geq 8$, $\mathrm{P}$ for trend $=0.015$ ) after adjustment for factors that can affect the psychological status.

Conclusion: We found that caffeine intake is associated weight, height, academic achievement, and higher score in BDI, BAI, ISI, and GARS. Caffeine intake was positively associated with the severity of depression and the severity of insomnia among adolescents in Korean.
\end{abstract}

Keywords: Adolescent; Caffeine Intake; Depression; Insomnia 


\section{INTRODUCTION}

Moderate caffeine intake has an awakening effect improving alertness and reducing fatigue by stimulating the nervous system. ${ }^{1,2)}$ It is reported that caffeine consumption through easily accessible coffee, sodas and chocolates has been increasing. ${ }^{3)}$ According to a report, there was a $13.3 \%$ of increase in the number of coffee house and $11.2 \%$ of increase in the coffee sales in 2013, comparing to those of 2012 and the caffeine consumption is increasing not only in adults but also in adolescents to reduce stress from entrance examination and sleeping time ${ }^{4)}$ but the understanding about caffeine and risk of overdose lacks. ${ }^{5)}$

When caffeine is absorbed, it reaches to the bloodstream in 20-45 minutes ${ }^{6}$ and is rapidly excreted with the half-life of $4-6$ hours. ${ }^{7)}$ Previous studies in adults demonstrated that moderate caffeine intake has an analgesic effect and caffeinated coffee delays hepatic fibrosis and reduces the risk of death from liver cirrhosis and helps control blood sugar level in diabetes as well as reduces the risks of Alzheimer's disease and Parkinson's disease and certain types of cancers. ${ }^{8-12)}$

Caffeine overdose causes adverse effects such as tachycardia, hypertension, nausea, vomiting and gastritis. ${ }^{13,14)}$ It is also known to be associated with irritability, insomnia, depression, and anxiety as well as seizure and stroke in some cases. ${ }^{8-10,15)}$ Especially, in adolescents, caffeine accelerates aggression, reduces sleeping hours, and increases the daytime sleepiness and administration of painkillers for headache. ${ }^{15,16)}$ Furthermore, it has a harmful effect on growth because it causes the loss of calcium and potassium. ${ }^{17)}$ Despite of the risks, several energy drinks contain caffeine levels ranging from 30 to $207 \mathrm{mg}$ per can or bottle. Considering the fact that recommended daily intake of caffeine for children and adolescents is $2.5 \mathrm{mg} / \mathrm{kg}$, it is reasonable to say that the risk is relatively higher in those populations. ${ }^{15,18)}$ Adolescents who are short of knowledge about caffeine and controlling ability are more vulnerable to the adverse effects and addiction given the current situation where energy drinks and coffee are highly accessible due to a rapidly growing market and caffeine is widely used in favorite foods. ${ }^{19)}$ In fact, Drug Abuse Warning Network reported that the number of emergency department visits involving energy drinks doubled from 10,068 visits in 2007 to 20,783 visits in 2011, patients aged 18 to 25 were most commonly involved in energy drink-related emergency department visits. ${ }^{20)}$ Energy drinks containing more caffeine than coffee and cola can cause attention problems, headache, anxiety, insomnia, overexcitement and hyperactivity and may even fatal when it is excessively taken or drunk with alcohol. ${ }^{20,21)}$

Although studies on caffeine drinks and consumption patterns have been continuously conducted in Korea to date, ${ }^{22,23)}$ researches on the physical and neuropsychological effects of caffeine in Korean adolescents lack. ${ }^{17)}$ Thus, this study aims to evaluate the relationship of caffeine intake with depression, anxiety, stress, and insomnia in Korean adolescents.

\section{METHODS}

\section{Subject and Study Period}

This study was conducted with the second and third year of middle school students from a middle school in Daegu between 23rd May 2014 and 30th May 2014. Data was collected using a self-reported questionnaire from 243 students. Of them, 9 students who either withdrew the consent or fail to complete psychological tests were excluded from this study, and a total of 234 students were included in the analyses. Informed consent was obtained from all subjects. The study was approved by institutional review board of a regional hospital (KNUH2015-02-033-001).

\section{Evaluation of Caffeine Intake}

Caffeine intake during the last 1 month was measured. All caffeinated drinks on the market were investigated and drinks and foods such as highly caffeinated energy drink, coffee, green tea, cola and chocolates were classified. The product names and pictures were provided as a reference and intake was examined. The investigated amount of intake was converted into the intake per day.

\section{Personal History}

Personal history in the questionnaire included current height and weight and changes of height and weight over the last 1 year, current smoking habit and alcohol intake over the last 1 month, a diagnosis of depression and treatment by medical doctors, and the presence of other psychological or physical diseases were included. Academic achievement was graded by every $10 \%$ and was self-reported by the students.

\section{Psychological Tests}

Beck Depression Inventory (BDI) which was developed to evaluate the severity of depression ${ }^{24)}$ was used for the assessment of depression in this study. In majority of Korean studies, the standard cut-off scores are as follows: 0-9 indicates minimal depression, 10-15 indicates mild depression, 16-23 indicates moderate depression, and 24-63 indicates severe depression. ${ }^{25)}$ For the assessment of anxiety, Beck Anxiety Inventory (BAI) was used. ${ }^{26)}$ In most of Korean studies, 22-26 is classified as anxiety that requires therapeutic intervention, 27-31 as severe anxiety, and 32 and above as extremely anxiety. ${ }^{27)}$ Insomnia was evaluated using Insomnia Severity Index (ISI). ISI, a measure of subjective severity of insomnia, developed by Bastien et al. ${ }^{28)}$ and modified by Korean Sleep Research Society in 2002 was used. Fifteen and above was interpreted as clinical insomnia. The level of stress was evaluated using Global Assessment of Recent Stress (GARS) and a higher score indicates a higher level of stress. ${ }^{29)}$ In this study, the average GARS of the subjects, 13 , was used as a criteria to compare the stress levels between the groups.

\section{Statistical Analysis}

Statistical analyses were conducted using IBM SPSS statistical software 
ver. 21.0 (IBM Co., Armonk, NY, USA) and the results were expressed as mean \pm standard deviation or number (\%). The subjects were divided into 4 groups according to caffeine intake. Pearson's chi-square test for nominal variables and analysis of variance test and Scheffe's test for continuous variables were used to compare the characteristics of each group. To evaluate the relationship of caffeine intake with depression, anxiety, the quality of sleep, and stress level, odds ratio (OR) and 95\% confidence interval were calculated using logistic regression analysis. A P-value $<0.05$ was considered to indicate statistical significance.

\section{RESULTS}

\section{General Characteristics of the Population}

A total of 234 adolescents in the second and third year of a middle school included 114 male (48.7\%) and 120 female (51.3\%) students and their average age was $15.86 \pm 0.34$ years old. The average height was $165.43 \pm 7.89 \mathrm{~cm}$ and the mean change of the height over the last 1 year was $4.68 \pm 10.67 \mathrm{~cm}$. The average weight was $55.50 \pm 12.30 \mathrm{~kg}$ and the mean change of the weight was $2.85 \pm 3.56 \mathrm{~kg}$. Of them, 16 students were clinically diagnosed with depression $(6.8 \%)$ by medical doctors, and 13 and 35 students were smokers (5.6\%) and alcohol drinkers (15.0\%), respectively. According to the self-reported academic achievement, 80 students (34.2\%), 92 students (39.3\%), and 60 students $(25.6 \%)$ reported to be in the top $30 \%, 31 \%-60 \%$, and the top $61 \%$, respectively. Two students who missed to fill out their academic achievement were classified into 'no response.' The average caffeine intake per month and per day were $777.51 \pm 1,237.36 \mathrm{mg}$ and

Table 1. General characteristics of study population $(n=234)$

\begin{tabular}{lc}
\hline \multicolumn{1}{c}{ Characteristic } & Value \\
\hline Age $(\mathrm{y})$ & $15.86 \pm 0.34$ \\
Sex & \\
Male & $114(48.7)$ \\
Female & $120(51.3)$ \\
Height $(\mathrm{cm})$ & $165.43 \pm 7.89$ \\
Weight $(\mathrm{kg})$ & $55.50 \pm 12.30$ \\
Height change $(\mathrm{cm})$ & $4.68 \pm 10.67$ \\
Weight change $(\mathrm{kg})$ & $2.85 \pm 3.56$ \\
Clinically diagnosed depression & $16(6.8)$ \\
Current smoking & $13(5.6)$ \\
Alcohol drinking & $35(15.0)$ \\
Self-reported academic grades* & \\
$\leq 30 \%$ & $80(34.2)$ \\
$31 \%-60 \%$ & $92(39.3)$ \\
$\geq 61 \%$ & $60(25.6)$ \\
Caffeine consumption & \\
Month (mg/mo) & $777.51 \pm 1,237.36$ \\
Day (mg/d) & $25.92 \pm 41.25$ \\
Energy drink consumption ${ }^{\dagger}$ & $24(10.3)$ \\
\hline
\end{tabular}

Values are presented as mean \pm standard deviation or number (\%).

*No-response: 2. 'Energy drinks are beverages that contain caffeine, taurine, vitamins, herbal supplements, and sugar or sweeteners and are marketed to improve energy, weight loss, stamina, athletic performance, and concentration. ${ }^{7)}$ In this study, it contains redbull, hot6, burn intense, monster, sol and so on.
$25.92 \pm 41.25 \mathrm{mg}$, and 24 students (10.3\%) reported that they drink more than a can of highly caffeinated energy drink per month (Table 1).

\section{Characteristics of Each Group}

The subjects were divided into 4 groups according to caffeine intake; Q1 includes ones who takes caffeine $\leq 4.00 \mathrm{mg} / \mathrm{d}$ (58 students); Q2 includes ones who takes caffeine 4.00-9.66 mg/d (59 students); Q3 includes ones who takes caffeine $9.68-27.36 \mathrm{mg} / \mathrm{d}$ (58 students); Q4 includes ones who takes caffeine $\geq 27.50 \mathrm{mg} / \mathrm{d}$ (59 students). There were no statistically significant differences in sex, history of depression, and smoking habit between the groups. The height $(\mathrm{cm})$ was taller in a group with a higher intake of caffeine (Q1, 164.20 $\pm 7.29 \mathrm{~cm}$; Q2, $164.80 \pm 7.28 \mathrm{~cm}$; Q3, $165.28 \pm 6.98 \mathrm{~cm} ; \mathrm{Q} 4,167.41 \pm 9.54 \mathrm{~cm} ; \mathrm{P}=0.137, \mathrm{P}$ for trend $=0.028)$ and the weight $(\mathrm{kg})$ was heavier in a group with a

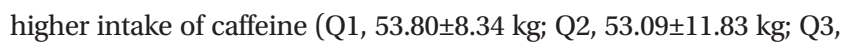
$55.90 \pm 11.30 \mathrm{~kg}$; Q4, $59.17 \pm 15.86 \mathrm{~kg}$; $\mathrm{P}=0.033$, P for trend=0.008) but there were no statistically significant difference in the changes of height and weight over the last 1 year between the groups. Alcohol intake was higher in a group with a higher intake of caffeine $(\mathrm{Q} 1,10.3 \%$; $\mathrm{Q} 2$, 6.8\%; Q3, 8.6\%; $\mathrm{Q} 4,33.9 \%)$ with a statistical significance $(\mathrm{P}<0.001$, $\mathrm{P}$ for trend $<0.001$ ). The students who reported to be in the top $61 \%$ of academic achievement (lower group) were 17.2\% (Q1), 25.4\% (Q2), 28.1\% (Q3), and 32.8\% (Q4). The differences were statistically significant and academic achievement was lower in a group with higher intake of caffeine ( $\mathrm{P}$ for trend $=0.005$ ). The scores of BDI of the groups were 7.07 $\pm 7.90(\mathrm{Q} 1), 7.66 \pm 6.88(\mathrm{Q} 2), 7.29 \pm 6.65(\mathrm{Q} 3)$, and 12.51 \pm 10.05 $(\mathrm{Q})$, which showed that BDI was higher in a group with higher intake of caffeine $(\mathrm{P}<0.001$, $\mathrm{P}$ for trend $=0.001)$. The scores of $\mathrm{BAI}$ of the groups were 5.52 $\pm 6.28(\mathrm{Q} 1), 6.81 \pm 6.76(\mathrm{Q} 2), 6.98 \pm 7.19(\mathrm{Q} 3)$, and 10.12 \pm 9.67 (Q4), demonstrating that BAI is higher in a group with higher intake of caffeine $(\mathrm{P}=0.010, \mathrm{P}$ for trend $=0.002)$. The ISI scores of the groups were

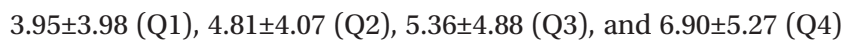
which showed that ISI is higher in a group with higher intake of caffeine $(\mathrm{P}=0.005$, $\mathrm{P}$ for trend $<0.001)$. The GARS of each group was $11.66 \pm 10.11$ (Q1), 11.73 $\pm 9.60(\mathrm{Q} 2), 12.41 \pm 10.03(\mathrm{Q} 3)$, and 16.53 \pm 12.81 (Q4) which also showed that GARS is higher in a group with higher intake of caffeine ( $\mathrm{P}=0.043, \mathrm{P}$ for trend=0.015) (Table 2 ).

\section{The Relationship of Caffeine Intake with Depression, Anxiety, Insomnia, Stress}

Logistic regression analysis was performed after adjusting sex, age, smoking habit, alcohol intake, history of depression, and academic achievement to evaluate the incidence of mild depression (BDI $\geq 10$ ) according to caffeine intake. The OR of Q2, Q3, and Q4 to Q1 were 0.94, 1.09 , and 2.95 which showed an increasing tendency and it was statistically significant ( $\mathrm{P}$ for trend=0.011). The OR of Q2, Q3, and Q4 to Q1 for the incidence of mild anxiety (BAI $\geq 22$ ) were $1.84,1.22$, and 2.78 which showed an increasing tendency but there was no statistical significance (P for trend=0.327). The OR of Q2, Q3, and Q4 to Q1 for the incidence of borderline insomnia (ISI $\geq 8$ ) were $1.00,2.41$, and 2.52, respectively, and the increasing tendency was statistically significant $(\mathrm{P}$ 
Table 2. Characteristics of the subjects according to caffeine intake groups

\begin{tabular}{|c|c|c|c|c|c|c|}
\hline \multirow{2}{*}{ Characteristic } & \multicolumn{4}{|c|}{ Quartiles of caffeine intake (mg/d) } & \multirow{2}{*}{ P-value* } & \multirow{2}{*}{ P for trend } \\
\hline & Q1 $(<4.00, n=58)$ & Q2 (4.00-9.66, n=59) & Q3 (9.68-27.36, n=58) & Q4 (>27.50, n=59) & & \\
\hline Age $(y)$ & $15.83 \pm 0.38$ & $15.86 \pm 0.35$ & $15.84 \pm 0.37$ & $15.92 \pm 0.28$ & 0.548 & 0.226 \\
\hline Sex & & & & & 0.985 & 0.769 \\
\hline Male & $28(48.3)$ & $28(28.7)$ & $28(28.3)$ & $30(28.7)$ & & \\
\hline Female & $30(51.7)$ & $31(52.5)$ & $30(51.7)$ & 29 (49.2) & & \\
\hline Height (cm) & $164.20 \pm 7.29$ & $164.80 \pm 7.28$ & $165.28 \pm 6.98$ & $167.41 \pm 9.54$ & 0.137 & 0.028 \\
\hline Weight (kg) & $53.80 \pm 8.34$ & $53.09 \pm 11.83$ & $55.90 \pm 11.30$ & $59.17 \pm 15.86$ & 0.033 & 0.008 \\
\hline Height change (cm) & $6.06 \pm 20.52$ & $3.66 \pm 3.07$ & $4.22 \pm 3.90$ & $4.78 \pm 3.96$ & 0.655 & 0.605 \\
\hline Weight change (kg) & $2.42 \pm 3.18$ & $2.43 \pm 3.22$ & $2.66 \pm 4.02$ & $3.88 \pm 3.64$ & 0.079 & 0.026 \\
\hline Depression history $^{\dagger}$ & & & & & $0.163^{\ddagger}$ & 0.067 \\
\hline DT & $0(0.0)$ & $2(3.4)$ & $0(0.0)$ & $2(3.4)$ & & \\
\hline DNT & $1(1.7)$ & $3(5.1)$ & $2(3.4)$ & $6(10.2)$ & & \\
\hline ND & $57(98.3)$ & $54(91.5)$ & $56(96.6)$ & $51(86.4)$ & & \\
\hline Current smoking & & & & & $0.087^{\ddagger}$ & 0.801 \\
\hline Yes & $5(8.6)$ & $1(1.7)$ & $1(1.7)$ & $6(10.2)$ & & \\
\hline No & $53(91.4)$ & $58(98.3)$ & 57 (98.3) & $53(89.8)$ & & \\
\hline Alcohol drinking & & & & & 0.000 & 0.000 \\
\hline Yes & $6(10.3)$ & $4(6.8)$ & $5(8.6)$ & $20(33.9)$ & & \\
\hline No & $52(89.7)$ & 55 (93.2) & $53(91.4)$ & $39(66.1)$ & & \\
\hline Self-reported academic grades ${ }^{\S}$ & & & & & 0.107 & 0.005 \\
\hline$\leq 30 \%$ & $26(44.8)$ & $22(37.3)$ & $21(36.8)$ & $11(19.0)$ & & \\
\hline $31-60 \%$ & $22(37.9)$ & $22(37.3)$ & $20(35.1)$ & $28(48.3)$ & & \\
\hline$\geq 61 \%$ & 10 (17.2) & $15(25.4)$ & $16(28.1)$ & 19 (32.8) & & \\
\hline Beck Depression Inventory & $7.07 \pm 7.90$ & $7.66 \pm 6.88$ & $7.29 \pm 6.65$ & $12.51 \pm 10.05$ & 0.000 & 0.001 \\
\hline Beck Anxiety Inventory & $5.52 \pm 6.28$ & $6.81 \pm 6.76$ & $6.98 \pm 7.19$ & $10.12 \pm 9.67$ & 0.010 & 0.002 \\
\hline Insomnia Severity Index & $3.95 \pm 3.98$ & $4.81 \pm 4.07$ & $5.36 \pm 4.88$ & $6.90 \pm 5.27$ & 0.005 & 0.000 \\
\hline Global Assessment of Recent Stress & $11.66 \pm 10.11$ & $11.73 \pm 9.60$ & $12.41 \pm 10.03$ & $16.53 \pm 12.81$ & 0.043 & 0.015 \\
\hline
\end{tabular}

Values are presented as mean \pm standard deviation or number (\%).

*Analysis of variance or Pearson's chi-square test. 'DT: diagnosed and treated, DNT: diagnosed and not treated, ND: not diagnosed. *Fisher's exact test. ${ }^{\S}$ Two non-responses were excluded $(n=232)$.

Table 3. Relationship between caffeine intake and depression, anxiety, insomnia, and stress

\begin{tabular}{|c|c|c|c|c|c|}
\hline & \multicolumn{4}{|c|}{ OR (95\% Cl) by quartiles of caffeine intake (mg/d) } & \multirow{2}{*}{ P for trend } \\
\hline & Q1 $(<4.00, n=58)$ & Q2 (4.00-9.66, $n=59)$ & Q3 (9.68-27.36, n=58) & Q4 (>27.50, $n=59)$ & \\
\hline Beck Depression Inventory $\geq 10$ (depression) & 1.00 & $0.94(0.40-2.19)$ & $1.09(0.47-2.50)$ & $2.95(1.29-6.76)$ & 0.011 \\
\hline Beck Anxiety Inventory $\geq 22$ (anxiety) & 1.00 & $1.84(0.29-11.67)$ & $1.22(0.16-9.63)$ & $2.78(0.46-16.78)$ & 0.327 \\
\hline Insomnia Severity Index $\geq 8$ (insomnia) & 1.00 & $1.00(0.36-2.75)$ & $2.41(0.96-6.08)$ & $2.52(0.98-6.53)$ & 0.015 \\
\hline Global Assessment of Recent Stress $\geq 13$ (stress) & 1.00 & $0.98(0.45-2.14)$ & $1.22(0.57-2.64)$ & $1.39(0.62-3.11)$ & 0.358 \\
\hline
\end{tabular}

Logistic regression analysis adjusted for sex, clinically diagnose depression, smoking, alcohol drinking, self-reported academic grades. Reference group: Q1. Q1 was compared with Q2, Q3, and Q4.

for trend=0.015). Due to the absence of the cutoff reference of GARS score, the average score of this study, 13, was used as the cutoff. The OR of Q2, Q3, and Q4 to Q1 for the stress were 0.98, 1.22, and 1.39 which showed an increasing tendency but there was no statistical significance ( $P$ for trend=0.358) (Table 3 ).

\section{DISCUSSION}

This study was conducted with a relatively large number of middle school students as a cross sectional study to evaluate the effects of caffeine intake on the psychological status of adolescents. The results showed that a group with a higher caffeine intake tends to have a high- er alcohol consumption, lower academic achievement and a higher score of depression, anxiety, insomnia, and stress. When influential factors were adjusted, the severity of depression and anxiety increased with statistical significance.

In this study, students who exceeded the recommended daily intake of caffeine were only $2 \%$. This result is contrasted to a previous study reporting that Korean adolescents tend to take a high dose of caffeine to keep awake during examination periods. ${ }^{30)}$ The reason for the discrepancy is that the data of this study was not collected during an examination period failing to reflect the intensive caffeine intake during an examination period. Moreover, the average daily caffeine intake in this study (25.92 mg) was slightly less than the average daily caffeine 
intake of adolescents reported by Korea's Ministry of Food and Drug safety in 2013 (30 mg). ${ }^{14)}$ The reason for the difference is thought that high school students with a relatively high purchasing power were included in the later report. Therefore, two studies are not comparable. Furthermore, the influence of study periods and study areas cannot be overlooked.

In our study, the amount of caffeine intake had a significant correlation with mild to severe depressive symptoms and borderline insomnia. This result is consistent with previous studies showing that caffeine intake influences sleep ${ }^{8-10,15,31)}$ and causes daytime sleepiness affecting academic achievement. In addition, persistent caffeine overdose can cause depression and lead to chronic depression as a withdrawal symptom even if caffeine intake is stopped. ${ }^{17,19,31)}$ This implies that caffeine intake should be warned considering the high suicide rate in Korea.

Several studies have demonstrated the relationship between caffeine and anxiety. ${ }^{31)}$ However, in this study, although the odds ratio showing the concurrence of mild to severe anxiety had an increasing, there was no statistical significance. The reason for this is that the study was conducted 2 weeks after the examination and anxiety might have been reduced at the point of the study period. Considering the fact that the half-life of caffeine is 4-6 hours, it is meaningless to measure anxiety after several days or weeks and chronic effects on cognitive function and emotion is expected to be trivial, too. The odds ratio between stress and caffeine intake showed an increasing tendency but there was no statistical significance, which is contrast to previous study results. It is thought that the discrepancy is caused by the facts that the stress level was measured some time after the caffeine intake not during the caffeine intake and other influential factors associated with stress were not considered in the analyses.

There are several limitations that need to be addressed in this study. Firstly, this study was conducted 2 weeks after the examination and the fact that caffeine overdose in adolescents is characterized by intensive overdose during a short period of time was not considered when the study was designed. Nevertheless, this limitation gave us an opportunity to examine usual habit and psychological status. Further studies on adverse effects of caffeine according to caffeine intake patterns by comparing the usual caffeine intake patterns and caffeine intake patterns during a specific period as well as the effects of addiction and withdrawal should be conducted. Secondly, this study was limitedly conducted with the second and third year of middle school students in a city. Therefore, selection bias cannot be excluded. The differences of psychological status and life patterns between middle school students and other students (elementary and high school students) were not considered. Moreover, students living in cities have a greater accessibility to caffeinated drinks than other areas. Thus, the results may differ depending on study locations. Thirdly, data was only collected by self-reported questionnaire. The height and weight were asked to the students instead of measuring them since the study was conducted in the school. Academic achievement and the diagnosis of depression were also not verified due to ethical issues. It is also possi- ble that the students were not completely honest during the psychological tests. Lastly, the causality of the relationship cannot be identified since the study was conducted as a cross sectional study.

Despite of the limitations, this study is significant because it is the first study that conducted with Korean middle school students to evaluate psychological effects of caffeine. Whereas the effects of caffeine are well investigated in other countries, data on Korean population lacks especially on adolescent population. In addition, this study showed that negative effects of caffeine are greater in adolescents comparing to adult population. The data can be used as evidence for health education. A large sample size $(n=234)$ of healthy adolescents and direct investigation using detailed and specified questionnaire are also the strong points.

Canned coffee, coffee mix, and carbonated drink that are highly accessible drinks contain a large amount of caffeine. ${ }^{14)}$ Sufficient education and warning on caffeine content and its effects is necessary and more studies on physical and psychological effects of caffeine with various ages and locations should be conducted.

\section{CONFLICT OF INTEREST}

No potential conflict of interest relevant to this article was reported.

\section{REFERENCES}

1. Griffiths RR, Juliano LM, Chausmer AL. Caffeine: pharmacology and clinical effects. In: Graham AW, Scultz TK, Mayo-Smith MF, Ries RK, Wilford BB, editors. Principles of addiction medicine. 3rd ed. Chevy Chase (MD): American Society of Addiction Medicine; 2003. p. 193224.

2. Ferre S. An update on the mechanisms of the psychostimulant effects of caffeine. J Neurochem 2008;105:1067-79.

3. Ahn YJ. Survey on the actual condition for adults' knowledge, attitude, and intake of caffeinated beverages [master's thesis]. Daegu: Keimyung University; 2010.

4. Kim MA. Investigation on teenager's perception and problems regarding high caffeine drinks: focuses on high caffeine and high taurine mixture [master's thesis]. Daegu: Kyungpook National University; 2013.

5. Chang YE, Chung HK. Survey of caffeine intake from children's favorite foods. Korean J Nutr 2010;43:475-88.

6. Liguori A, Hughes JR, Grass JA. Absorption and subjective effects of caffeine from coffee, cola and capsules. Pharmacol Biochem Behav 1997;58:721-6.

7. Denaro CP, Benowitz NL. Caffeine metabolism. In: Watson RL, editor. Liver pathology and alcohol: drug and alcohol abuse reviews. Totowa (NJ): Humana Press Inc.; 1991. p. 513-39.

8. Gunja N, Brown JA. Energy drinks: health risks and toxicity. Med J Aust 2012;196:46-9.

9. Carrillo JA, Benitez J. Clinically significant pharmacokinetic interactions between dietary caffeine and medications. Clin Pharmacokinet 2000;39:127-53.

10. Clark MA, Finkel R, Ray JA, Whalen K. Lippincott's illustrated reviews: 
pharmacology. 5th ed. Baltimore (MD): Lippincott Williams \& Wilkins; 2012. p. 151-60.

11. Cano-Marquina A, Tarin JJ, Cano A. The impact of coffee on health. Maturitas 2013;75:7-21.

12. O'Keefe JH, Bhatti SK, Patil HR, DiNicolantonio JJ, Lucan SC, Lavie CJ. Effects of habitual coffee consumption on cardiometabolic disease, cardiovascular health, and all-cause mortality. J Am Coll Cardiol 2013; 62:1043-51.

13. Kim SH. Study of establishment recommended daily allowance for caffeine [Internet]. Seoul: Korea Food and Nutrition Foundation; 2007 [cited 2007 Nov 5]. Available from: http://report.ndsl.kr/repDetail. do? $\mathrm{cn}=\mathrm{TRKO} 201000014956 \&$ topN=1.

14. Kim MH, Choi DS, Choi JC, Lee SH. How much is the caffeine intake level of Koreans? [Internet]. Cheongju: Ministry of Food and Drug Safety; 2013 [cited 2013 Aug 6]. Available from: http://www.mfds. go.kr/index.do?mid=675\&seq=20953.

15. Kang SH, Yoo HN, Chung SH, Kim CY. Eveningness, sleep patterns, daytime sleepiness and fatigue in Korean male adolescents. Sleep Med Psychophysiol 2012;19:89-96.

16. Son HS. The prevalence and correlates of taking painkillers for headache in high school students [master's thesis]. Seoul: Ewha Womans University; 2007.

17. Seifert SM, Schaechter JL, Hershorin ER, Lipshultz SE. Health effects of energy drinks on children, adolescents, and young adults. Pediatrics 2011;127:511-28.

18. Do YS, Kang SH, Kim HT, Yoon MH, Choi JB. Investigation on the consumption of caffeinated beverages by high school students in Gyeonggi-do. J Food Hyg Saf 2014;29:105-16.

19. Reissig CJ, Strain EC, Griffiths RR. Caffeinated energy drinks: a growing problem. Drug Alcohol Depend 2009;99:1-10.

20. Substance Abuse and Mental Health Services Administration. Update on emergency department visits involving energy drinks: a continuing public health concern [Internet]. Rockville (MD): Substance Abuse and Mental Health Services Administration; 2013 [cited 2013 Jan 10].
Available from: http://www.samhsa.gov/data/2k13/DAWN126/sr126energy-drinks-use.pdf.

21. Rath M. Energy drinks: what is all the hype?: the dangers of energy drink consumption. J Am Acad Nurse Pract 2012;24:70-6.

22. Sim HW. Factors related to the consumption of caffeinated beverages in some high school students [dissertation]. Seoul: Kyunghee University; 2010.

23. Kim SM. A study on the consumption of caffeinated drinks of high school students: focused on Geoje-si, Gyeongsangnam-do [master's thesis]. Suncheon: Sunchon National University; 2012.

24. Beck AT, Ward CH, Mendelson M, Mock J, Erbaugh J. An inventory for measuring depression. Arch Gen Psychiatry 1961;4:561-71.

25. Min SS, Kim ZS, Park KB. The cut-off score for the Korean version of Beck Depression Inventory. Korean J Clin Psychol 1993;12:71-81.

26. Beck AT, Epstein N, Brown G, Steer RA. An inventory for measuring clinical anxiety: psychometric properties. J Consult Clin Psychol 1988;56:893-7.

27. Yuk SP, Kim JS. The clinical study of Korean version of Beck Anxiety Inventory: comparison of the patients and normal. Korean J Clin Psychol 1997;16:185-97.

28. Bastien CH, Vallieres A, Morin CM. Validation of the Insomnia Severity Index as an outcome measure for insomnia research. Sleep Med 2001;2:297-307.

29. Koh KB, Park JK. Validity and reliability of the Korean version of the Global Assessment of Recent Stress Scale. Korean J Psychosom Med 2000;8:201-11.

30. Lee JE, Huh W, Choi EJ. Pattern analysis of high-caffeine energy drink consumption and adverse effects among college students in a university. Yakhak Hoeji 2013;57:110-8.

31. Bernstein GA, Carroll ME, Crosby RD, Perwien AR, Go FS, Benowitz NL. Caffeine effects on learning, performance, and anxiety in normal school-age children. J Am Acad Child Adolesc Psychiatry 1994;33:40715. 